\title{
Quantitative Proteomics Analysis of Ischemia/Reperfusion Injury-Modulated Proteins in Cardiac Microvascular Endothelial Cells and the Protective Role of Tongxinluo
}

\author{
Qing Lia He-He Cuib Yue-Jin Yang ${ }^{a}$ Xiang-Dong Li ${ }^{a}$ Gui-Hao Chen ${ }^{a}$ \\ Xia-Qiu Tian ${ }^{\mathrm{a}}$ Chen Jin ${ }^{\mathrm{a}}$ Qiu-Ting Dong ${ }^{\mathrm{a}}$ Pei-Sen Huanga Jun $\mathrm{Xu}^{\mathrm{a}}$

\begin{abstract}
aState Key Laboratory of Cardiovascular Disease, Fuwai Hospital, National Center for Cardiovascular Diseases, Chinese Academy of Medical Sciences and Peking Union Medical College, Beijing,

${ }^{b}$ Department of Cardiology, Beijing Friendship Hospital, Capital medical university, Beijing, China
\end{abstract}

\section{Key Words}

Proteomics • Cardiac microvascular endothelial cells $•$ Ischemic/reperfusion injury • Tongxinluo

\begin{abstract}
Background: The protection of endothelial cells (ECs) against reperfusion injury has received little attention. In this study, we used Tandem Mass Tag (TMT) labeling proteomics to investigate the modulated proteins in an in vitro model of cardiac microvascular endothelial cells (CMECs) subjected to ischemia/reperfusion (I/R) injury and their alteration by traditional Chinese medicine Tongxinluo (TXL). Methods: Human CMECs were subjected to $2 \mathrm{~h}$ of hypoxia followed by $2 \mathrm{~h}$ of reoxygenation with different concentrations of TXL. Protein expression profiles of CMECs were determined using tandem mass spectrometry. We evaluated several proteins with altered expression in I/R injury and summarized some reported proteins related to I/R injury. Results: TXL dose-dependently decreased CMEC apoptosis, and the optimal concentration was $800 \mu \mathrm{g} / \mathrm{mL}$. I/R significantly altered proteins in CMECs, and 30 different proteins were detected between a normal group and a hypoxia and serum deprivation group. In I/R injury, TXL treatment up-regulated 6 types of proteins including acyl-coenzyme $A$ synthetase ACSM2B mitochondrial (ACSM2B), cyclin-dependent kinase inhibitor 1B (CDKN1B), heme oxygenase 1 (HMOX1), transcription factor SOX-17 (SOX17), sequestosome-1 isoform 1 (SQSTM1), and TBC1 domain family member 10B (TBC1D10B). Also, TXL down-regulated 5 proteins including angiopoietin-2 isoform c precursor (ANGPT2), cytochrome c oxidase assembly factor 5 (COA5), connective tissue growth factor precursor (CTGF), cathepsin L1 isoform 2 (CTSL), and eukaryotic elongation factor 2 kinase (LOC101930123). These types of proteins mainly had vital functions, including cell proliferation, stress response, and regulation of metabolic process. Conclusions: The study presented differential proteins upon I/R injury through a proteomic analysis. TXL modulated the expression of proteins in CMECs and has a protective role in response to I/R.




\section{Introduction}

Microvascular disturbance is a crucial mechanism of myocardial ischemia/reperfusion injury (MIRI), and numerous mechanisms are involved in the process, including inflammation and oxidative stress [1], calcium overload and $\mathrm{pH}$ alterations [2]. As a basic component of the myocardial microcirculation, CMECs have a critical role in the protection of cardiomyocytes against MIRI [3]. Although CMECs are more sensitive to the reperfusion injury than cardiomyocytes [4], endothelial cells (ECs) have received considerably less attention in relation to reperfusion injury. To date, few studies have been published to clarify the proteins in CMECs in MIRI and to describe the functions and interactions of the altered proteins.

Proteomics is a potential tool to study the large-scale expression, function, and interaction of the complement of proteins in an organism in health and disease [5, 6]. Recent advances in proteomics technology allow the evaluation of systematic changes in protein expression in response to MIRI. During the past decade, several proteomic approaches have revealed potential alterations of the cardiac proteins in cardiomyocytes in different I/R states $[7,8]$. However, limited systematic research has focused on ECs to explore the modulation mechanisms during I/R.

Tongxinluo (TXL), a traditional Chinese medicine, was approved for treatment and is widely used among patients with cardiovascular diseases in China [9]. Previous studies demonstrated that TXL has pleiotropic effects, such as vasodilatation, lipid lowering effects, anti-inflammation and anti-oxidation activity $[10,11]$. Moreover, our previous studies have found that TXL can protect CMECs against I/R injury by the induction of autophagy and enhancement of endothelial nitric oxide synthase (eNOS) activity [12-14]. However, whether TXL regulates CMECs and the interaction of different proteins secreted by CMECs in MIRI remains unknown.

In this study, we used Tandem Mass Tag (TMT) quantitative proteomics [15] to detect the various proteins in an in vitro model of CMEC I/R injury with TXL treatment. Our aims are to investigate whether I/R can modulate the proteins of CMECs in MIRI as a whole and to synthetically analyze the underlying mechanism of TXL.

\section{Materials and Methods}

\section{Preparation of the TXL solution}

TXL ultra-fine powder (Yiling Pharmaceutical Co., Hebei, China) was dissolved in Dulbecco's modified Eagle's medium (DMEM, Life Technologies, Grand Island, USA). The preparation of TXL solution was performed as previous described [11].

\section{Cell culture and treatment}

Human CMECs (San Diego, USA) were cultured in endothelial cell medium (ECM, ScienCell) containing $5 \%$ fetal bovine serum, $1 \%$ endothelial cell growth supplement and $1 \%$ penicillin/streptomycin at $37^{\circ} \mathrm{C}$ with $5 \% \mathrm{CO}_{2}$. To determine the optimal concentration of TXL, cells were exposed to different concentrations $(200,400,800$, and $1200 \mu \mathrm{g} / \mathrm{mL})$ of TXL in serum-free DMEM under hypoxia/serum deprivation (H/SD) conditions. Cells were put into a sealed GENbox hypoxic chamber fitted with an AnaeroPack (Mitsubishi Gas Chemical Company, Japan) to scavenge the free oxygen at $37^{\circ} \mathrm{C}$ for $2 \mathrm{~h}$, and removed to normal circumstance for $2 \mathrm{~h}$ of reoxygenation. The oxygen concentration was maintained below $0.1 \%$ after $0.5-1 \mathrm{~h}$ as indicated by an Anaer indicator (Bio-Merieux, Marcy I'Etoile, France). CMECs were divided into three groups for TMT labeling proteomics analysis: CMECs in normal conditions (Group N), CMECs in H/SD conditions (Group HR), and CMECs treated with TXL in H/SD conditions (Group HR+TXL). For the HR and HR+TXL groups, the cells were incubated in H/SD conditions for $2 \mathrm{~h}$ and in normal conditions for an additional $2 \mathrm{~h}$. For the HR+TXL group, cells were simultaneously treated with the optimal concentration of TXL.

Apoptosis assay

Cell apoptosis was assessed by an Annexin V-PE detection kit (BD, USA) according to the manufacturer's instructions. The stained cells were immediately analyzed using a FACS Calibur flow cytometer and Cell 


\section{Cellular Physiology Cell Physiol Biochem 2017;41:1503-1518

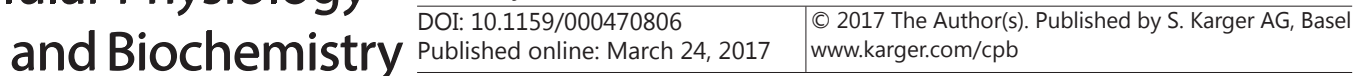

Li et al.: Proteomics in CMECs after I/R and TXL Treatment

Quest software (BD, USA). Apoptotic rates were calculated among the different groups to confirm the optimal concentration of TXL.

\section{Protein sample preparation}

The cultured cells of the three groups were collected and the lysates were centrifuged at 13,000 g for $15 \mathrm{~min}$ at $4{ }^{\circ} \mathrm{C}$, and then the supernatants were collected and frozen at $-80^{\circ} \mathrm{C}$ until use. Protein concentrations were quantified by BCA protein assays.

Proteomic analysis

According to the results of the BCA assay, aliquots of $100 \mu \mathrm{g}$ of each sample in $1.5 \mathrm{~mL}$ centrifuge tubes were used for peptide labeling with TMT 9-plex according to the manufacturer's protocol (Pierce, TMT® Mass Tagging Kits and Reagents Kits). Q Exactive mass spectrometer (Thermo Scientific) was applied for the identification and quantification of proteins by secondary mass spectrometry. A high performance liquid chromatography (HPLC) system (Diane NCS3500 system) was used with a mass range of 350 to 1500 $\mathrm{m} / \mathrm{z}$. Ten precursor ions exhibiting the most intense signals were selected for secondary mass spectrum identification. Fragment ion spectra produced via high-energy collision dissociation (HCD) were required for secondary mass spectrometry sequencing. The original data of mass spectrometry detection were quantitatively generated via the proportion of ions. The sequence of differential peptides was obtained from database (humanrefseq121101.fasta, 31182 entries). The work was performed at the Capitalbio Research Center, China.

\section{Bioinformatic analysis}

Briefly, 1.5-fold increases or reductions were defined as the standard for proteins exhibiting significant changes. The Entrez database was used to identify corresponding gene symbols or gene IDs. We used a hierarchical clustering algorithm for the clustering of samples and proteins. The functional annotation of differentially expressed proteins was obtained from the Gene Ontology (GO) database. Furthermore, protein interaction networks were built with the GeneMANIA Cytoscape plugin and GNCpro (http://gncpro. sabiosciences.com/gncpro/gncpro.php).

\section{Protein expression and functional identification}

We chose HMOX1 and ANGPT2 for further experiments to identify the expression and function of the differential proteins. CMECs were divided into N, H/R, TXL $(800 \mu \mathrm{g} / \mathrm{mL}$ ), TXL+TiiPPIX (Tin Protoporphyrin

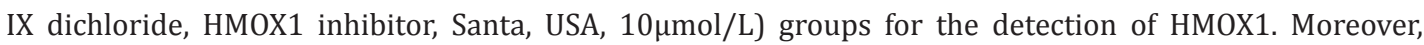
CMECs were assigned to N, H/R, TXL, TXL+ANGPT2 Plasmid (Santa, USA), TXL+Control Plasmid (Santa, USA) groups for detection of ANGPT2. After $2 \mathrm{~h}$ of hypoxia followed by $2 \mathrm{~h}$ of reoxygenation, further analysis were applied including western blot analysis, CCK8 assay, cell migration assay, tube formation assay.

\section{Western blot analysis}

Proteins were extracted from CMECs and the concentrations were established by BCA protein assay. Equal amounts of proteins (30 mg protein/lane) were electrophoresed, transferred to nitrocellulose membranes (Life Technologies) and blocked. The membranes were incubated with primary antibodies against $\beta$-actin (1:1000 dilution; Zhongshanjinqiao, China), HMOX1, ANGPT2 (1:1000 dilution, Abcam, USA). Then, the membranes were incubated with peroxidase-conjugated secondary antibodies at 1:5000. After washing, the membranes were analyzed by a chemifluorescent reagent ECL (Thermo Scientific, Rockford, IL, USA). Band intensities were quantified and calculated.

\section{Cell proliferation assay with CCK-8}

3000 cells per well cells were seeded in 96-well plated. The proliferation rate was determined by the Cell Counting Kit-8 (CCK-8) according to the protocol (Dojindo, Japan). $10 \mu$ per well of CCK-8 reagent was added when the cells grew for $24 \mathrm{~h}$ and $48 \mathrm{~h}$. Absorbance at $450 \mathrm{~nm}$ was measured after incubation for $1 \mathrm{~h}$ with CCK-8.

Cell migration assay

Transwell assay was used to detect the cell migration. CMECs were seeded on the upper chamber of the Transwell ( $8 \mu \mathrm{m}$, Corning, USA). The lower chamber was added with ECM without FBS. After $4 \mathrm{~h}$ of 
Li et al.: Proteomics in CMECs after I/R and TXL Treatment

incubation, the non-migrated cells were removed from the top of the filter using cotton swabs, then cells that had migrated to the bottom were fixed in crystal violet for $2 \mathrm{~h}$, and counted.

Tube formation assay

48-well plated was coated with $200 \mu \mathrm{l}$ Matrigel (BD Biosciences, USA) and incubated at $37^{\circ} \mathrm{C}$ for 30 min to form gels. $2 \times 10^{4}$ cells per well cells were seeded and incubated with $2 \%$ FBS ECM for $4 \mathrm{~h}$. The length of the tubes and the branches number were measured using Image J software.

\section{Statistical analysis}

All measurements were presented as the averages of three independent replicates. Differences of the protein expression among the three groups were tested by one-way analysis of variance (ANOVA). Least Significant Difference (LSD) test was used for post hoc test in ANOVA. All these analyses were performed with SPSS 18.0 software (SPSS Inc, Chicago, IL, USA). All tests were two-sided, p-value $<0.05$ was considered as statistically significant.

\section{Results}

TXL decreased apoptosis of CMECs in a concentration-dependent manner

To investigate the protective role of TXL on CMECs under hypoxia/reoxygenation (H/R) conditions, cells with different concentrations of TXL were detected by flow cytometry (Fig. 1). The apoptotic rate of CMECs had a significant increase with H/R injury compared with the control group $(28.73 \pm 0.64 \%$ vs. $5.81 \pm 0.61 \%, p<0.05)$. TXL dose-dependently attenuated $\mathrm{H} / \mathrm{R}$-induced apoptosis, and the best protective effect was noted with $800 \mu \mathrm{g} / \mathrm{mL}$ TXL.

Fig. 1. Anti-apoptotic effect of TXL on CMECs. A. Representative pictures from each group. Annexin V-/PI- cells were viable cells. Annexin V+/PI- cells were early apoptotic cells. Annexin V $\pm / P I+$ cells were necrotic or apoptotic cells in terminal stages. B. Quantifications of the apoptotic CMECs are presented as the percentage of early apoptotic cells. ${ }^{*} p<0.05$ vs. Normal; ${ }^{\#} p<$ 0.05 vs. H/R.

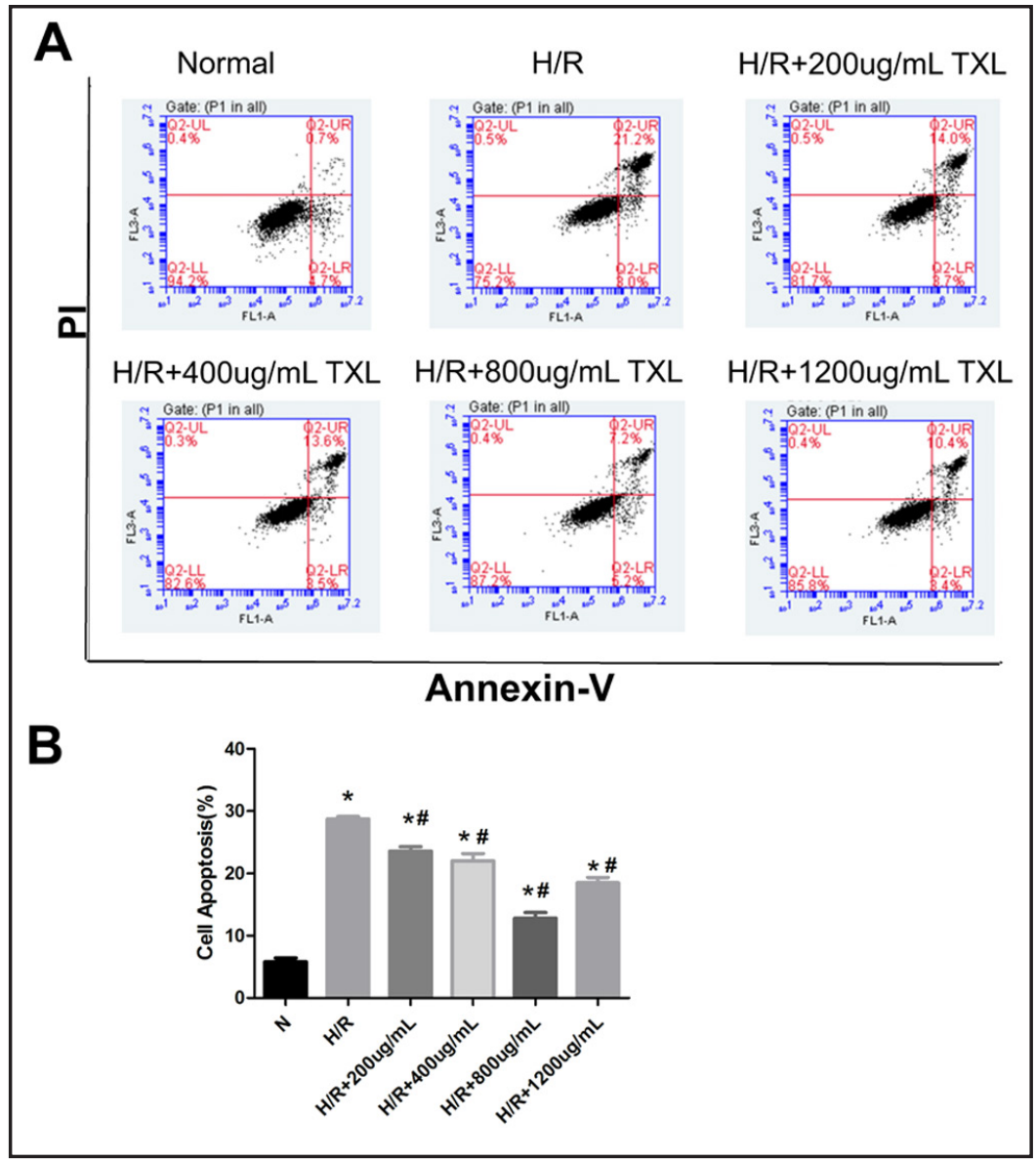




\section{Cellular Physiology Cell Physiol Biochem 2017;41:1503-1518 and Biochemistry Published onlIne: VIarch 24, $2017 \quad \begin{aligned} & \text { DOI: 10.1159/000470806 } 2017 \text { The Author(s). Published by S. Karger AG, Basel } \\ & \text { www.karger.com/cpb }\end{aligned}$

Fig. 2. Clustering analysis of the 50 differentially expressed proteins in nine samples. H/R: Hypoxia/Reoxygenation. Protein names corresponded to gene symbols: HMOX1, heme oxygenase 1; RGCC, regulator of cell cycle RGCC; SOX17, transcription factor SOX17; PSIP1, PC4 and SFRS1-interacting protein isoform 2; GLS, glutaminase kidney isoform, mitochondrial isoform 1; CYP1A1, cytochrome P450 1A1; CDKN1B, cyclin-dependent kinase inhibitor 1B; TBC1D10B, TBC1 domain family member 10B; SQSTM1, sequestosome-1 isoform 1; ACSM2B, acyl-coenzyme A synthetase ACSM2B, mitochondrial; SDF4, $45 \mathrm{kDa}$ calcium-binding protein isoform 2 precursor; CTSL, cathepsin L1 isoform 2; ANGPT2, angiopoietin-2 isoform c precursor; UBL5, ubiquitin-like protein 5; LOC101930123, eukaryotic elongation factor 2 kinase; COA5, cytochrome c oxidase assembly factor 5; THBS1, thrombospondin-1 precursor; CTGF, connective tissue growth factor precursor; POSTN2_precursor, periostin isoform 2 precursor; POSTN3_precursor, periostin isoform 3 precursor; RPS27L, 40S

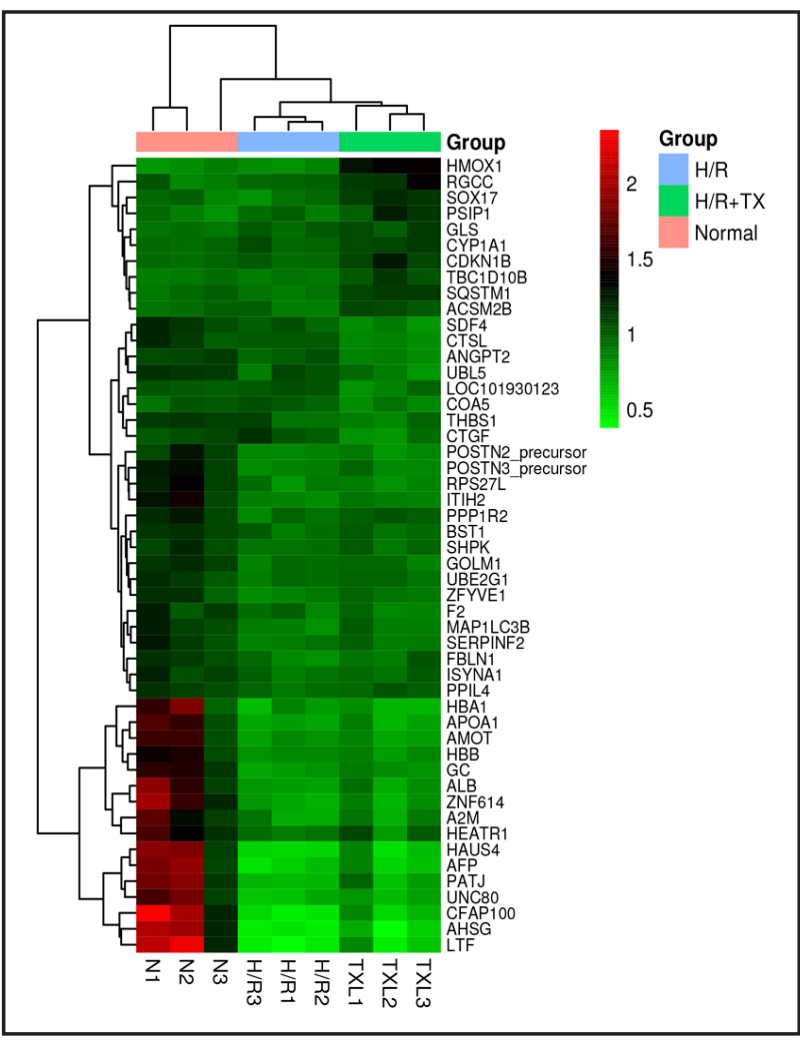
ribosomal protein S27-like; ITIH2, inter-alpha-trypsin inhibitor heavy chain H2 precursor; PPP1R2, protein phosphatase inhibitor 2; BST1, ADP-ribosyl cyclase 2 precursor; SHPK, sedoheptulokinase; GOLM1, Golgi membrane protein 1; UBE2G1, ubiquitin-conjugating enzyme E2 G1; ZFYVE1, zinc finger FYVE domain-containing protein 1 isoform 2; F2, prothrombin preproprotein; MAP1LC3B, microtubule-associated proteins 1A/1B light chain 3B; SERPINF2, alpha-2-antiplasmin isoform b precursor; FBLN1, fibulin-1 isoform D precursor; ISYNA1, inositol-3-phosphate synthase 1 isoform 4; PPIL4, peptidyl-prolyl cis-trans isomerase-like 4; HBA1, hemoglobin subunit alpha; APOA1, apolipoprotein A-I preproprotein; AMOT, angiomotin isoform 2; HBB, hemoglobin subunit beta; GC, vitamin D-binding protein isoform 1 precursor; ALB, serum albumin preproprotein; ZNF614, zinc finger protein 614; A2M, alpha-2-macroglobulin precursor; HEART1, HEAT repeat-containing protein 1; HAUS4, HAUS augmin-like complex subunit 4 isoform 2; AFP, alpha-fetoprotein precursor; PATJ, crumbs cell polarity complex component; UNC80, protein unc-80 homolog isoform 2; CFAP100, cilia and flagella associated protein 100. AHSG, alpha-2-HS-glycoprotein preproprotein; LTF, lactotransferrin isoform 2.

$I / R$ significantly change the proteins level of CMECS, and TXL treatment further changed the protein expression

To detect the proteins of CMECs after H/R and how it is modulated by TXL, we used tandem mass tag labeling proteomics to reveal the change of proteins. CMECs in normal conditions (Group N), CMECs in H/R conditions (Group HR), and CMECs treated with TXL in $\mathrm{H} / \mathrm{R}$ conditions (Group HR+TXL) were detected respectively, and TXL at $800 \mu \mathrm{g} / \mathrm{mL}$ was used because of its optimal effect of anti-apoptosis. There were three repetitions in each group.

Clustering analysis. Clustering analysis of nine samples was done according to all detected proteins and the differential proteins, respectively. The results of three independent replicates of each group were showed in Fig. 2. There were substantial differences in the expression of proteins among three groups.

Analysis of differential proteins. Among the 4537 detected proteins, 50 differentially expressed proteins were identified totally in three groups by TMT-labeled proteomics using 
Fig. 3. A. Compared with the $\mathrm{N}$ group, 30 proteins were significantly decreased in the HR group. B. Compared with the HR group, 11 proteins were significantly altered in the TXL+HR group. Six proteins were up-regulated, and 5 proteins were down-regulated. Proteins names corresponded to gene symbol refer to Fig. 2.

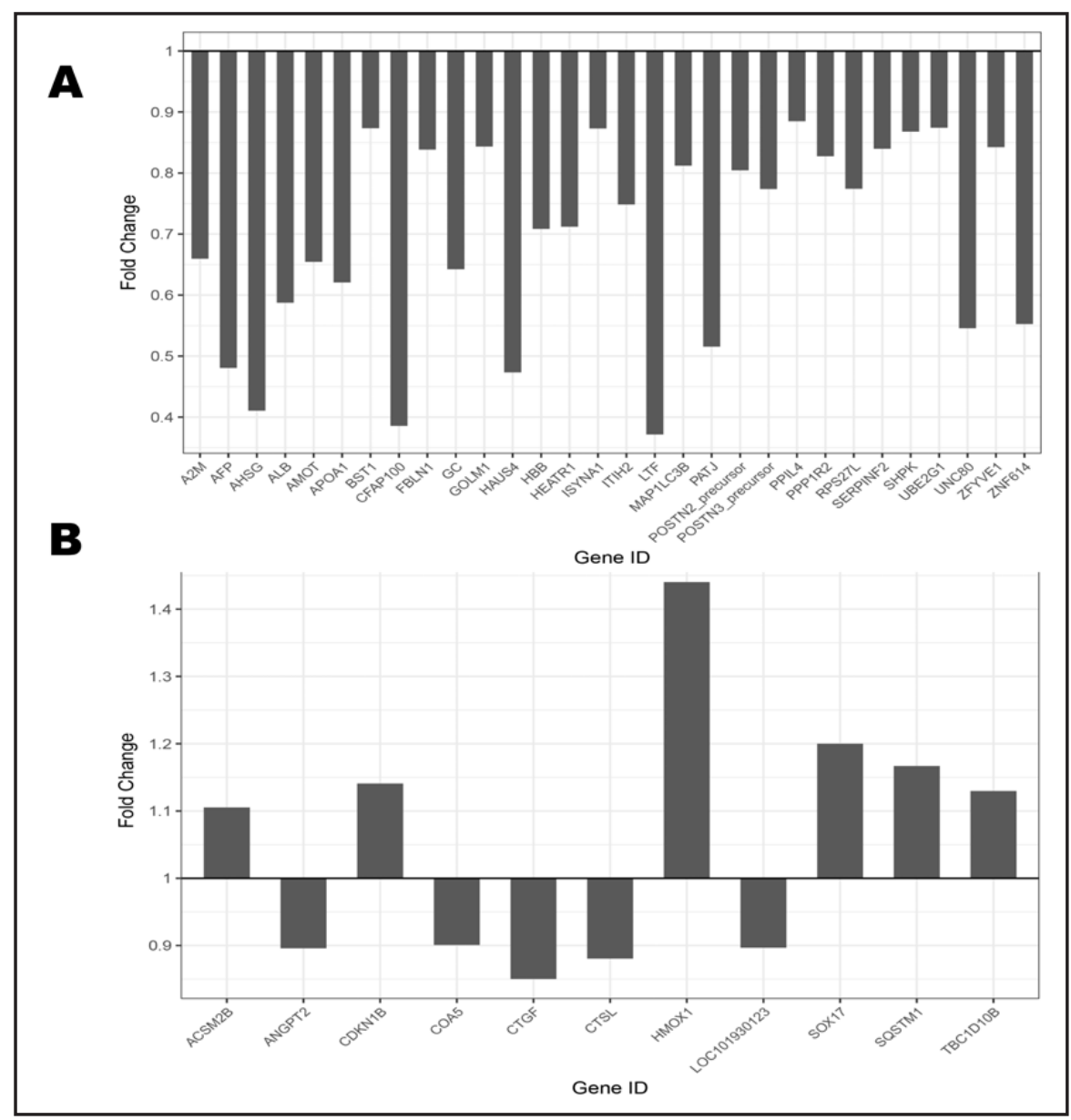

ANOVA analysis $(p<0.05)$, every identified protein had 1.5 fold change at least. These values are expressed on a log scale.

Compared with group N, 30 proteins were significantly down-regulated in group HR, among which lactoferrin (lactotransferrin isoform 2, LTF) has the largest decline (Fig. 3A). Compared with group HR, TXL $800 \mu \mathrm{g} / \mathrm{mL}$ treatment up-regulated 6 proteins and down-regulated 5 proteins. HMOX1 and precursor of connective tissue growth factor (connective tissue growth factor, CTGF) had the largest up-regulation and down-regulation, respectively (Fig. 3B). Top 10 representative differential proteins between different groups had been showed in Suppl. Table 1 (for all online suppl. material, see www.karger.com/ doi/10.1159/000470806).

There were 6 proteins obviously down-regulated in H/R injury and up-regulated to normal level through TXL treatment (Fig. 4A). There were 9 proteins with no obvious change in $\mathrm{H} / \mathrm{R}$ injury but up-regulated significantly than normal through TXL treatment. Among them, the level of 5 proteins in group HR+TXL was much higher than group HR and the level of 4 proteins showed no statistical significance (Fig. 4B). There were 7 proteins with no obvious change in H/R injury but down-regulated significantly than normal through TXL treatment. Among them, the level of 2 proteins in group HR+TXL was much lower than group HR and 5 proteins level showed no statistical significance (Fig. 4C).

Gene Ontology (GO) analysis. Functions of differentially expressed proteins among three groups were detected by GO analysis (see supplementary material, Suppl. Table 2). The functions of differential proteins in the H/R included negative regulation of hydrolase activity, humoral immune response, regulation of inflammatory response, regulation of response to external stimulus, platelet degranulation, acute inflammatory response, and regulation of biomineral tissue development. TXL treatment could significantly change the 


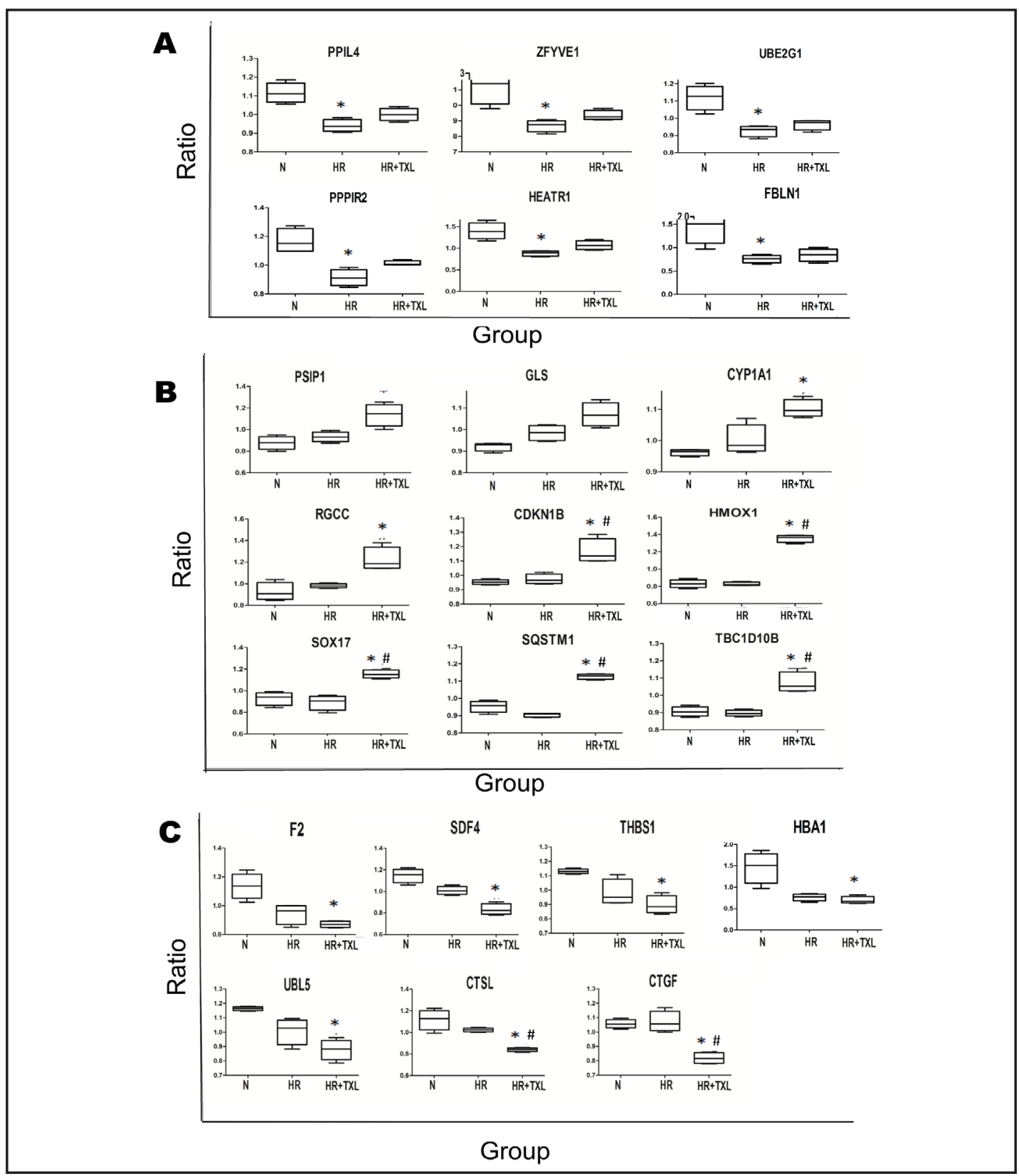

Fig. 4. Differential protein analysis. A. Six proteins obviously down-regulated upon hypoxia/reoxygenation injury returned to normal levels upon TXL treatment. B. Nine proteins with no obvious change upon hypoxia/reoxygenation injury were significantly up-regulated upon TXL treatment. C. Seven proteins with no obvious change in hypoxia/reoxygenation injury were significantly down-regulated compared with the control upon TXL treatment. PPIL4, peptidyl-prolyl cis-trans isomerase-like 4; ZFYVE1, zinc finger FYVE domain-containing protein 1 isoform 2; UBE2G1, ubiquitin-conjugating enzyme E2 G1; PPP1R2, protein phosphatase inhibitor 2; HEART1, HEAT repeat-containing protein 1; FBLN1, fibulin-1 isoform D precursor; PSIP1, PC4 and SFRS1-interacting protein isoform 2; GLS, glutaminase kidney isoform, mitochondrial isoform 1; CYP1A1, cytochrome P450 1A1; RGCC, regulator of cell cycle RGCC; CDKN1B, cyclin-dependent kinase inhibitor 1B; HMOX1, heme oxygenase 1; SOX17, transcription factor SOX-17; SQSTM1, sequestosome-1 isoform 1; TBC1D10B, TBC1 domain family member 10B; F2, prothrombin preproprotein; SDF4, 45 kDa calcium-binding protein isoform 2 precursor; THBS1, thrombospondin-1 precursor; HBA1, hemoglobin subunit alpha; UBL5, ubiquitin-like protein 5; CTSL, cathepsin L1 isoform 2; CTGF, connective tissue growth factor precursor. ${ }^{*} p<0.05$ vs. $\mathrm{N}$; ${ }^{\#} p<0.05$ vs. HR. 
Fig. 5. Functions and pathways of accumulated differentially expressed proteins. (Enrichment $p$-value < 0.05). Protein names corresponded to gene symbols: CP, ceruloplasmin; USP6NL, USP6 N-terminal-like protein; APOC2, apolipoprotein C-II; BMP6, bone morphogenetic protein 6; AGTR1, type-1 angiotensin II receptor; TGFBR3, transforming growth factor beta receptor type 3; ALDH7A1, alpha-aminoadipic semialdehyde dehydrogenase; USF2, upstream stimulatory factor 2; CD47, leukocyte surface antigen CD47; SELPLG, p-selectin glycoprotein ligand 1; EPS8, EGF receptor pathway substrate 8 .

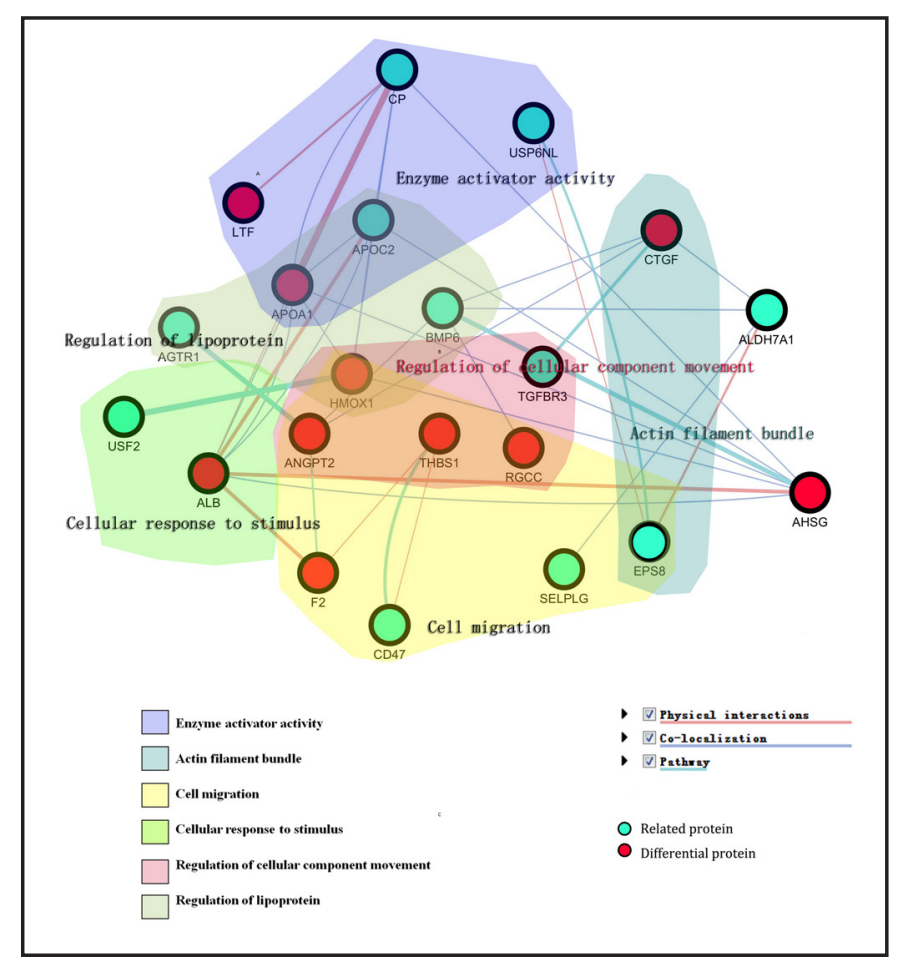

expression of many proteins. These proteins played an important role in the areas mainly including response to oxygen levels, response to hypoxia, negative regulation of cellular component movement, regulation of response to stimulus, cell motility, cell migration, collagen metabolic process, regulation of developmental process, and cellular component movement.

Functions and pathways of differential proteins. We also analyzed functions and pathways of differentially expressed proteins according to enrichment p-value (Fig. 5). These functions and pathways included cellular response to stimulus, cell migration, regulation of cellular component movement, regulation of lipoprotein, actin filament bundle, and enzyme activator activity (Fig. 5). Some proteins had more than one function such as HMOX1, angiopoietin-2 isoform c precursor (ANGPT2), connective tissue growth factor precursor (CTGF), apolipoprotein A-I preproprotein (APOA1).

Identification and functional analysis of HMOX and the regulation of TXL. Western analysis was performed in order to identify the expression of HMOX (Fig. 6A, B). The expression of HMOX had no significant difference between group H/R and group N, while it was significantly unregulated $(p<0.05)$ in TXL group compared with other groups. Furthermore, the addition of HMOX inhibitor had no change of the protein expression. To determine the function of HMOX during H/R in CMECs, further analysis were performed. Flow cytometry results indicated that, compared with the control group, H/SD significantly increased the percentage of apoptotic cells $(6.60 \pm 2.05 \%$ vs. $23.23 \pm 2.78 \%$ in control group, $p<0.05)$. Conversely, TXL treatment led to a decrease $(14.53 \pm 1.53 \%)$ in apoptotic cells induced by H/SD and the anti-apoptotic effect of TXL was largely reduced by HMOX inhibitor TinPPIX (32.90 $\pm 2.33 \%$ ) (Fig. 6C, D). As shown in Fig. 6E, CCK8 assay showed that inhibition of HMOX led to remarkably reduction of cell proliferation than TXL treatment alone both at $24 \mathrm{~h}(0.13 \pm 0.02$ vs. $0.44 \pm 0.40$ in TXL group, $p<0.05)$ and $48 \mathrm{~h}(0.34 \pm 0.07$ vs. $0.62 \pm 0.02$ in TXL group, $p<0.05$ ) after H/R. Moreover, similar trend was observed in the cell migration assay and tube formation assay. TXL treatment significantly promoted the cell migration and angiogenesis than cells exposed to H/R condition. When cells were cultured with TinPPIX and TXL, the number of migrated cells, the tube length, and the branches number were significantly reduced compared with TXL group (Fig. 6F, G, H, I). 
Fig. 6. Identification and functional analysis of HMOX and the regulation of TXL. A. The expression of HMOX and $\beta$-actin detected by western blot. B. Quantitative analysis of the expression of HMOX/ $\beta$-actin was shown in the bar graphs. C, D. Apoptosis was quantified by FACS analysis of Annexin V and PI positive cells. E. Proliferation assay. Value of OD450 was detected by enzyme-labeled instrument determined with CCK-8 assay. F. Migration assay. Cells were photographed under a phase-contrast microscope at $200 \times$ magnification. G. Tube formation assay. Tubes were photographed under a phase-contrast microscope at $200 \times$ magnification. H. The number of migrated cells was counted using Image J software. I. Tube formation was represented by the relative tube length and the relative branches number calculated by Image J software. Each column represents mean \pm SD of three independent experiments. ${ }^{*} p<0.05$ vs. N; ${ }^{\#} p<0.05$ vs. H/R; ${ }^{\$} p<$ 0.05 vs. TXL.

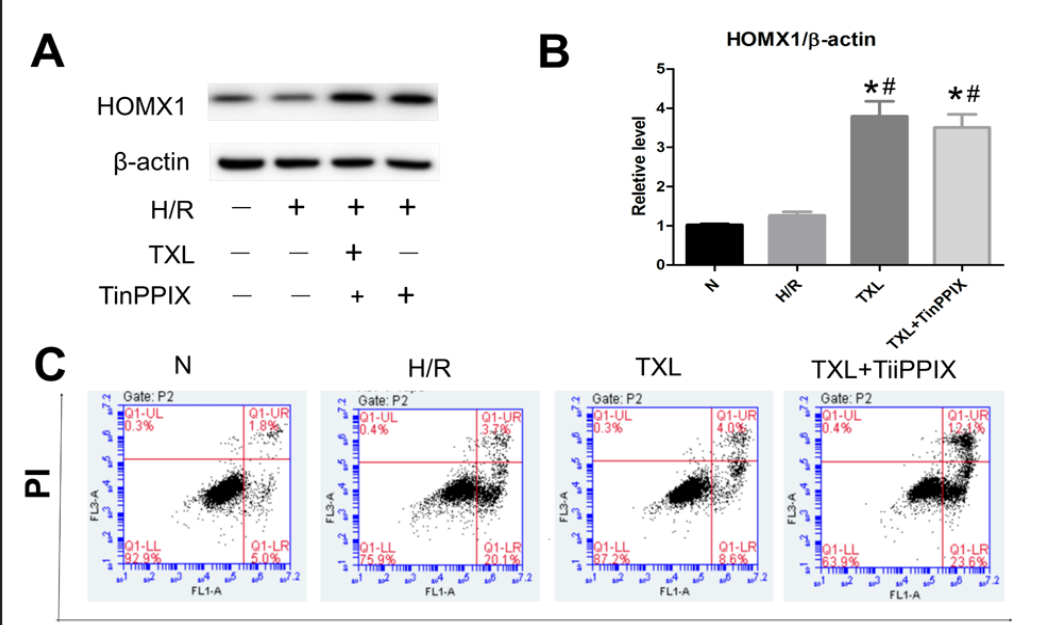

Annexin-V

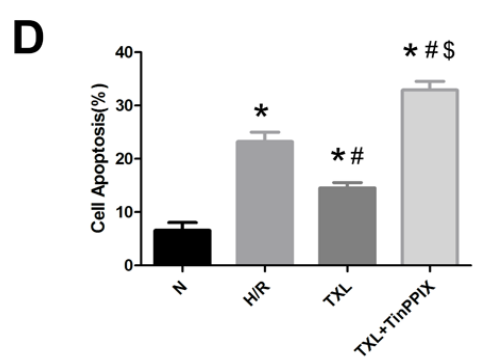

E

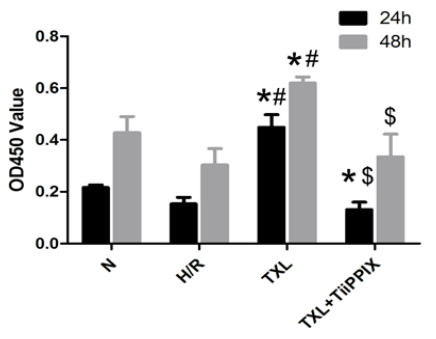

$\mathbf{F}$ $\mathrm{N}$
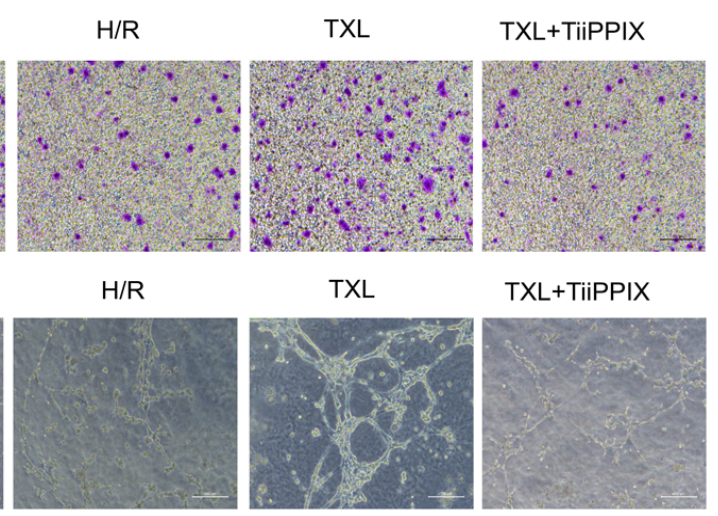

G

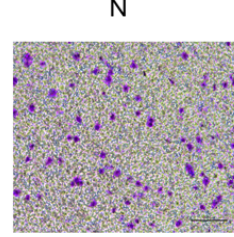

N

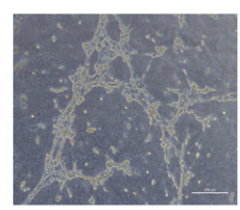

$\mathbf{H}$

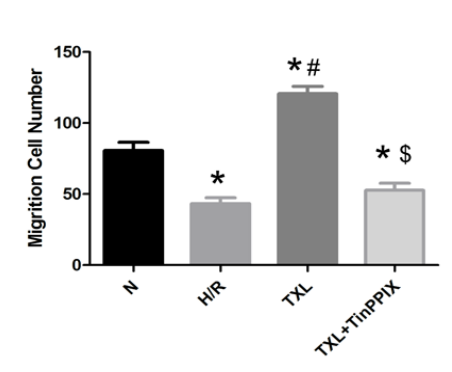

TXL

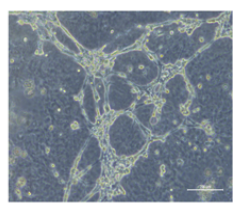

TXL+TiiPPIX
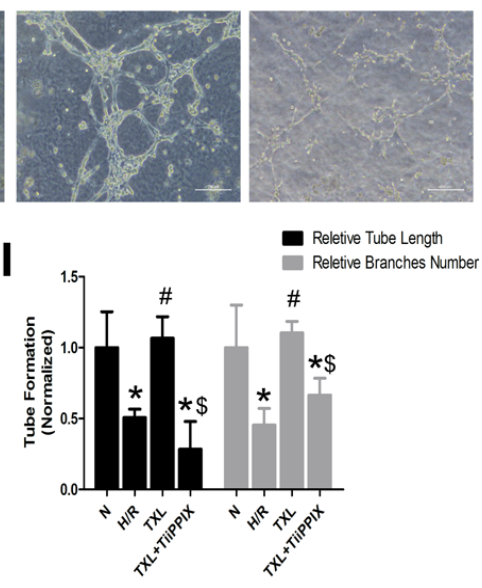

Identification and functional analysis of ANGPT2 and the regulation of TXL. The expression of ANGPT2 was detected by western blot and no significant difference was observed between group $\mathrm{H} / \mathrm{R}$ and group $\mathrm{N}$, while it was significantly down-regulated $(p<$ 0.05 ) in TXL group compared with H/R group. Moreover, the addition of ANGPT2 plasmid led to overexpression of ANGPT2 (Fig. 7A, B). As shown in Fig. 7C, D, cell apoptosis was 
Fig. 7. Identification and functional analysis of ANGPT2 and the regulation of TXL. A. The expression of ANGPT2 and $\beta$-actin detected by western blot analysis. B. Quantitative analysis of the expression of ANGPT2/ $\beta$-actin was shown in the bar graphs. C, D. Apoptosis was quantified by FACS analysis of Annexin $\mathrm{V}$ and PI positive cells. E. Proliferation assay. Value of OD450 was detected by enzyme-labeled instrument determined with CCK-8 assay. F. Migration assay. Cells were photographed under a phase-contrast microscope at $200 \times$ magnification. G. Tube formation assay. Tubes were photographed under a phase-contrast microscope at $200 \times$ magnification. $H$. The number of migrated cells was counted using Image J software. I. Tube formation was represented by the relative tube length and the relative branches number calculated by Image J software. Each column represents mean \pm SD of three independent experiments. ${ }^{*} p<0.05$ vs. $\mathrm{N}$; ${ }^{\#} p<0.05$ vs. $\mathrm{H} / \mathrm{R} ;{ }^{\$} p<0.05$ vS. TXL.

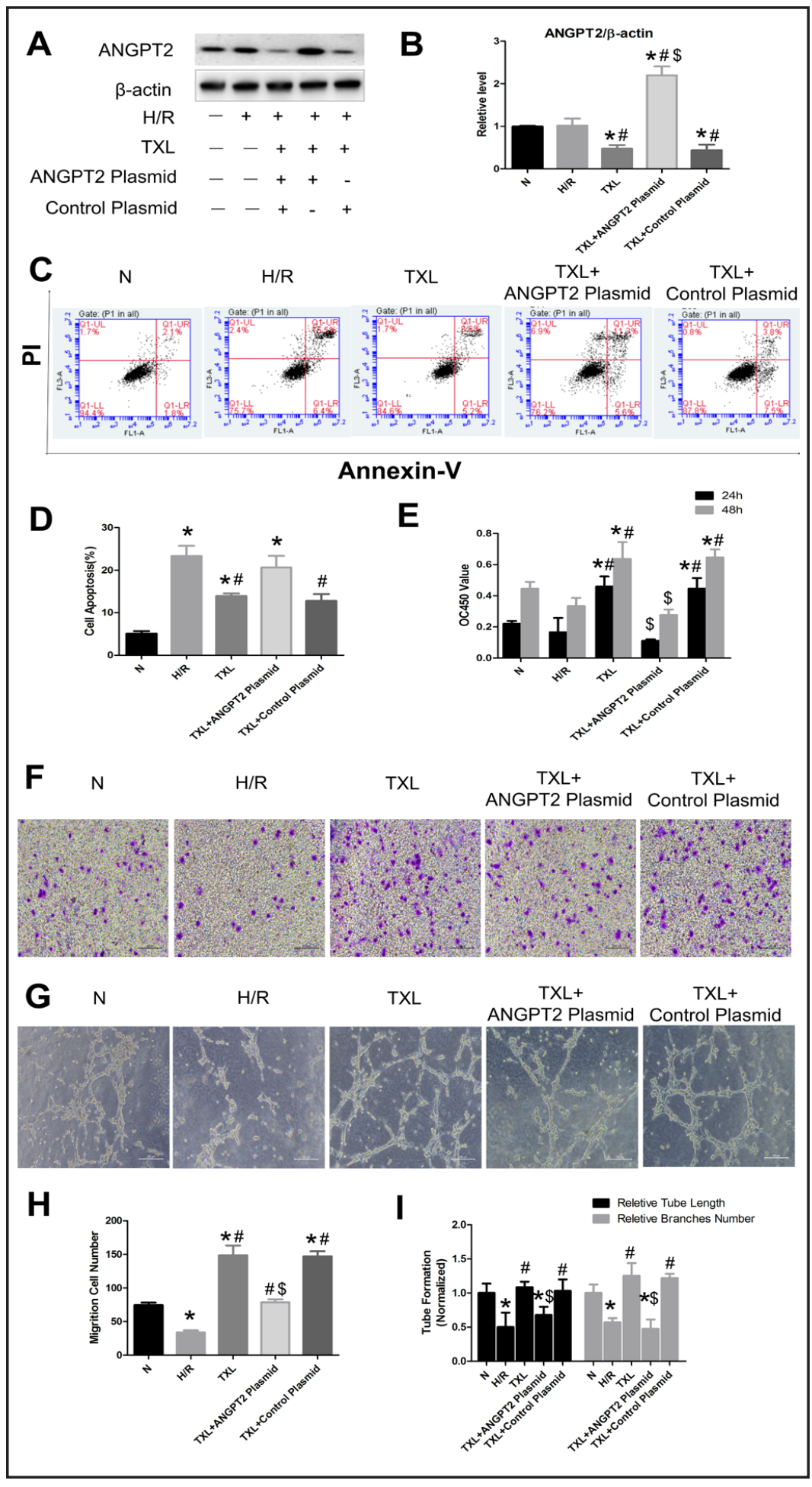

measured by flow cytometry and showed significant decrease in TXL group than H/R group $(13.93 \pm 0.82 \%$ vs. $23.33 \pm 3.40 \%$ in HR group, $p<0.05)$. Conversely, the anti-apoptotic effect of TXL was largely reduced by combined treatment with ANGPT2 plasmid $(13.93 \pm 0.82 \%$ vs. $20.63 \pm 3.89 \%$ in TXL+ANGPT Plasmid group, $p<0.05$ ). As displayed in Fig. 7E, compared with H/R group, TXL treatment remarkably increased cell proliferation at $24 \mathrm{~h}(0.46 \pm 0.05$ vs. $0.17 \pm 0.07 \mathrm{in} \mathrm{H/R}$ group, $p<0.05)$ and $48 \mathrm{~h}(0.64 \pm 0.09$ vs. $0.33 \pm 0.04 \mathrm{in} \mathrm{H/R}$ group, $p$ $<0.05$ ) after H/R injury. These effects of TXL were largely attenuated when combination of 
ANGPT2 overexpression. Also, the pro-migration and pro-angiogenesis effects of TXL were significantly reduced when cells were cultured with both ANGPT2 plasmid and TXL (Fig. 7F, G, H, I).

\section{Discussion}

Endothelial dysfunction is considered as the initiating process and pathological basis of myocardial no-reflow and reperfusion injury [16]. TXL has been proved to effectively improve the cardiac microcirculation in previous studies $[17,18]$. However, there is no explicit mechanism responsible for IR and the regulation by TXL. In this study, we utilized an acute in vitro CMEC ischemia/reperfusion injury model $(2 \mathrm{~h} / 2 \mathrm{~h})$ and TMT-labeled proteomic analysis to detect the proteins in CMECs during I/R and its modulation by TXL. To the best of our knowledge, this is the first study to 1) systematically investigate the change of proteins in endothelial cells during I/R and to 2) explore the multiple mechanisms of the regulation at the whole cell level by firstly using proteomic analysis. Also, we find that TXL treatment can affect the level of proteins in CMECs.

We identified 50 differentially expressed proteins using TMT-labeled proteomics, which permits fast quantitative profiling of a large number of proteins from complex biological samples. We found that $\mathrm{H} / \mathrm{R}$ could significantly alter the levels of 32 proteins. These proteins had different functions and are involved in a variety of processes during I/R. Alpha-2macroglobulin precursor (A2M), APOA1, alpha-2-HS-glycoprotein preproprotein (AHSG), and sedoheptulokinase (SHPK) were down-regulated in CMECs during I/R in response to inflammation and oxygen stress. The expression of these pro-inflammatory proteins was increased in serum upon acute inflammation [19-23]. Feedback regulation might be involved in reducing the secretion of these proteins in CMECs. LTF is an iron-binding glycoprotein and involved in several biological functions, including iron absorption, antioxidative activities, and regulating the systemic immune response [24]. The present study showed that LTF is significantly down-regulated in CMECs during I/R, similar to a previous study [25]. According to the classical research of Ambrosio [26], the no-reflow area has a large number of neutrophils and substantial platelet aggregation, which may be the main cause of capillary vessel embolism. The intracellular levels of A2M, serum albumin preproprotein (ALB), and APOA1 decreased, and these proteins participated in the regulation of platelet degranulation, leading to cell aggregation, which has not been previously reported.

We summarized some I/R-related proteins in previous studies and analyzed their relationships, such as P-selection (SELP), erythropoietin (EPO), hypoxia inducible factor-1 (HIF1), thromboxane synthase (TBSAX1), tryptophan hydroxylase 1 (TPH1), superoxide dismutase 1 (SOD1), matrix metalloproteinase-1 (MMP1), interleukin 8 (IL8), monocyte chemoattractant protein-1 (CCL2), and tumor necrosis factors(TNF). They were identified in several studies to take part in the regulation of multiple cellular processes. These proteins were classified according to gene ontology entries in GeneMANIA. The GeneMANIA analysis predicted a potential interaction among all these reported proteins, which were summarized (see supplementary material, Suppl. Fig. 1). Inflammation and oxidative stress have been widely accepted to be key pathological processes of CMECs. In our analysis, we identified a complete network of proteins associated with I/R. In the case of ischemia and hypoxia, vascular and endothelial tissues may release inflammatory factors, including HIF [18], SOD1, $\mathrm{NF} \kappa \mathrm{B}[27,28]$. ECs normally regulate the release of vasoconstriction factors (ET1, TXA2) and diastolic factors (prostaglandins and adenosine oxidase) to maintain balance, which is disrupted in ischemia-reperfusion injury [29]. The adhesion molecules P-selectin and ICAM1 are involved in mediating the cell adhesion effect between neutrophils and ECs during I/R [30]. Furthermore, as a family of more than twenty secreted and cell-surface end peptidases, matrix metalloproteinases (MMPs) also participate in the process [31]. Our analysis further explored their interaction as the supplement of the previous studies. For example, NFKB could down-regulate the expression of MARK1, thus inhibiting the expression of TNF. 
Conversely, it could also be up-regulated and chemically modified by MARK1. In addition, NF $\kappa$ B was up-regulated by IL1B, IL-8, IL18 and HIF, however, it had different effects on these proteins. It could down-regulate the expression of HIF, while it had a co-expression effect and physical interaction with IL1B, IL-8. Also, CCL2 was found to have the physical interaction and predicted TFactor regulation with $\mathrm{NF \kappa B}$. There was still some unclear interactions among different factors, such as between NFKB and SOD1.

Accumulating studies suggest that TXL mediates endothelium preservation in a mechanism that improves cardiac functions $[12,32,33]$. In the previous studies, we have found that TXL protects ECs against MIRI through the PKA/CREB/eNOS pathway [13] and protects endothelial connections through regulating the expression of VE-cadherin [34]. We demonstrated in the present study that TXL protected CMECs against I/R injury via the regulation of various proteins and the activation of different pathways regulated by these proteins. Here, we introduce some representative proteins and their functions and biological processes.

Several proteins, such as peptidyl-prolyl cis-trans isomerase (PPIL) and HEAT repeatcontaining protein 1 (HEATR1), were down-regulated by I/R but up-regulated with TXL treatment in our study. For example, the stress-responsive protein PPIL4, which is involved in protein folding, reactive oxygen species neutralization, and stress protection accumulated [35]. However, no related research regarding these proteins explored their functions in MIRI. These proteins were obviously down-regulated during I/R, whereas TXL treatment up-regulated their expression in CMECs, which may be a part of the protective mechanism of TXL. Through the GO analysis, we found that these proteins were involved in different functions and pathways.

In the present study, some proteins exhibited no significant difference in CMECs during I/R but decreased with TXL treatment. Angiopoietin-2 (ang2, ANGPT2), a negative regulator of angiogenesis [36], is stored in ECs and released in response to homeostatic reactions including inflammation and hypoxia $[37,38]$. Ang2 disrupts EC-EC junctions and induces vascular leakage in various stress conditions [39]. CTGF regulates cell adhesion, migration, and the production of extracellular matrix (ECM) proteins in various biological processes [40]. It was demonstrated that H/R increased CTGF expression in ECs and influenced fibroblast differentiation into myofibroblasts [41]. This finding is consistent with our forecast and may suggest the following mechanisms of TXL: anti-fibrosis, enhancement of angiogenesis, and vasodilatation effects. As shown in Fig. 5 and (see supplementary material) Suppl. Table 2, CTGF was involved in the regulation of actin filament bundling, whereas ANGPT2 had an effect on the regulation of cell migration, cellular component movement, and cellular response to stimulus. As mentioned above, our study demonstrated that TXL significantly decreased the expression of ANGPT2 under H/R condition, whereas combined treatment of TXL with overexpression of ANGPT2, the anti-apoptotic, pro- proliferation, pro-migration, pro-angiogenesis effects of TXL were remarkably attenuated, indicating that ANGPT2 had a negative regulation of cell survival, cell proliferation, cell migration and angiogenesis in CMECs. Silencing ANGPT2 expression may be one of the critical protective mechanisms of TXL.

Our study showed that TXL increased the expression of various protective proteins in CMECs during I/R. Sox17 is an important factor in angiogenesis, vascular remodeling and EC differentiation, which could induce functional angiogenesis after cerebral ischemia [42]. HOMX1 is a stress response and cytoprotective protein and protects cardiomyocytes against I/R injury through generating the antioxidant bilirubin and the anti-inflammatory substance carbon monoxide (CO) in rat hearts [43]. RGCC is involved in cellular differentiation, inflammation and fibrosis and is a cell cycle activator [44]. These proteins participated in the response to oxygen levels, response to stimulus, cell migration, and cell proliferation in our study. To further validate the functions of HMOX detected by GO analysis, HMOX inhibitor TinPPIX was applied. It was observed that targeted inhibition of HMOX significantly eliminated the protective effects of TXL on H/SD-induced apoptosis, and suppressed cell migration, cell proliferation, and tube formation. In this regard, it is reasonable to conclude 
that HMOX was one of protective proteins mediating the beneficial effects of TXL in our study, which correlate well with the previous reports. In addition, these proteins had complicated effects with different proteins, such as APOA1, which is involved in the regulation of lipoprotein and enzyme activator activity. Other proteins, such as SQSTM1, had no related reports in previous studies. In our study, these proteins were involved in the regulation of cell autophagy and cell apoptosis and the response to stimulus during IR. Furthermore, TXL significantly decreased the levels of ANGPT2, CTGF, and CTSL. These proteins were related to oxidative stress, inflammatory, metabolic and biosynthetic processes in our analysis.

There are some limitations of our study. First, we use TMT-labeled proteomic to detect the expression of 4537 proteins which have been already known. However, some unknown proteins or proteins outside the detected proteins may be neglected. Second, our study only focus on the regulation of protein level, thus, more molecular biology experiments are needed in further study. Third, the expression of these proteins and their functions may change over time with the progress of the ischemia reperfusion injury. Hence, more time points for testing may be necessary.

In summary, TMT labeling proteomics is a method to comprehensively study I/R injury upon TXL treatment at the molecular level. We identified 50 differentially expressed proteins in CMECs that were connected to ischemia reperfusion injury and involved in numerous functions and pathways. I/R significantly altered the expression of various proteins in CMECs, whereas TXL treatment modulated factor secretion. These findings suggested that TXL may protect microvascular ECs against I/R injury through inhibition of inflammatory chemokine secretion, reductions in oxidative stress factors, and regulation of multicellular metabolic processes.

\section{Abbreviations and acronyms of proteins}

ACSM2B (acyl-coenzyme A synthetase ACSM2B, mitochondrial); AFP (alpha-fetoprotein precursor); AGTR1 (type-1 angiotensin II receptor); AHSG (alpha-2-HS-glycoprotein preproprotein); ALB (serum albumin preproprotein); ALDH7A1 (alpha-aminoadipic semialdehyde dehydrogenase); AMOT (angiomotin isoform 2); ANGPT2 (angiopoietin-2 isoform c precursor); APOA1 (apolipoprotein A-I preproprotein); APOC2 (apolipoprotein C-II); A2M (alpha-2-macroglobulin precursor); BMP6 (bone morphogenetic protein 6); BST1 (ADP-ribosyl cyclase 2 precursor); CCL2 (monocyte chemoattractant protein-1); CDKN1B (cyclin-dependent kinase inhibitor 1B); CD47 (leukocyte surface antigen CD47); CFAP100 (cilia and flagella associated protein 100); COA5 (cytochrome c oxidase assembly factor 5); CP (ceruloplasmin); CRP (C-reaction protein); CTGF (connective tissue growth factor precursor); CTSL (cathepsin L1 isoform 2); CYP1A1, (cytochrome P450 1A1); END1 (endothelin); EP0, (erythropoietin); EPS8 (EGF recepto pathway substrate 8); FBLN1 (fibulin-1 isoformD precursor); FGF2 (fibroblast grow factors-2); F2 (prothrombin preproprotein); GC (vitamin D-binding protein isoform 1 precursor); GLS (glutaminase kidney isoform, mitochondrial isoform 1); GOLM1 (Golgi membrane protein 1); GPX1 (glutathione peroxidase 1); HAUS4 (HAUS augmin-like complex subunit 4 isoform 2); HBA1 (hemoglobin subunit alpha); HBB (hemoglobin subunit beta); HEART1 (HEAT repeat-containing protein 1); HIF1 (hypoxia inducible factor-1); HMOX1 (heme oxygenase 1); ICAM2, (intercellular adhesion molecules); IL1B (interleukin 1); IL8 (interleukin 8); IL18 (interleukin 18); ITIH2 (inter-alpha-trypsin inhibitor heavy chain $\mathrm{H} 2$ precursor); ISYNA1 (inositol-3-phosphate synthase 1 isoform 4); JUN (v-jun avian sarcona virus 17 oncogene homolog); LOC101930123 (eukaryotic elongation factor 2 kinase); LTF (lactotransferrin isoform 2); MAP1LC3B (microtubuleassociated proteins 1A/1B light chain 3B); MARK1 (microtubule affinity-regulating kinase 1); MMP1 (matrix metalloproteinase-1); NFKB (nuclear factor $\kappa B$ ); PATJ (crumbs cell polarity complex component); POSTN2_precursor (periostin isoform 2 precursor); POSTN3_ precursor (periostin isoform 3 precursor); PPIL4 (peptidyl-prolyl cis-trans isomerase-like 4); PPP1R2 (protein phosphatase inhibitor 2); PSIP1 (PC4 and SFRS1-interacting protein 
isoform 2); RGCC (regulator of cell cycle RGCC); RPS27L (40S ribosomal protein S27-like); SDF4 (45 kDa calcium-binding protein isoform 2 precursor); SELP (P-selection); SELPLG (p-selectin glycoprotein ligand 1); SERPINF2 (alpha-2-antiplasmin isoform b precursor); SHPK (sedoheptulokinase); SOD1 (superoxide dismutase 1); SOX17 (transcription factor SOX-17); SQSTM1 (sequestosome-1 isoform 1); TBC1D10B (TBC1 domain family member 10B); TBSAX1 (thromboxane synthase); TGFBR3 (transforming growth factor beta receptor type 3); THBS1 (thrombospondin-1 precursor); TNF (tumor necrosis proteins); TPH1 (tryptophan hydroxylase 1); UBL5 (ubiquitin-like protein 5); UBE2G1 (ubiquitin-conjugating enzyme E2 G1); UNC80 (protein unc-80 homolog isoform 2); USF2 (upstream stimulatory factor 2); USP6NL (USP6 N-terminal-like protein); VEGFA (vascular endothelial growth factor A); XDH (xanthine dehydrogenase/oxidase); ZFYVE1 (zinc finger FYVE domain-containing protein 1 isoform 2); ZNF614 (zinc finger protein 614).

\section{Acknowledgments}

This work was supported by grants from the National Natural Science Foundation of China (81200107, 81603425), the 973 Program of China (2012CB518602), the Beijing Talents Fund (No. 2016000021469G221), and Rising Star Program from Beijing Friendship Hospital, CMU (No.YYQDKT2015-25). Thanks Doctor Cui Hehe for the contributions in experimental design, performed experiments and interpreted data.

\section{Disclosure Statement}

The authors have no potential conflict of interests to declare.

\section{References}

1 Wang HB, Yang J, Ding JW, Chen LH, Li S, Liu XW, Yang CJ, Fan ZX, Yang J: RNAi-Mediated Down-Regulation of CD47 Protects against Ischemia/Reperfusion-Induced Myocardial Damage via Activation of eNOS in a Rat Model. Cell Physiol Biochem 2016;40:1163-1174.

- Bekkers SC, Yazdani SK, Virmani R, Waltenberger J: Microvascular obstruction: Underlying pathophysiology and clinical diagnosis. J Am Coll Cardiol 2010;55:1649-1660.

3 Shimomura H, Terasaki F, Hayashi T, Kitaura Y, Isomura T, Suma H: Autophagic degeneration as a possible mechanism of myocardial cell death in dilated cardiomyopathy. Jpn Circ J 2001;65:965-968.

-4 Arun K. Singhal JDSS, Shiu YE: Role of endothelial cells in myocardial ischemia-reperfusion injury. Vasc Dis Prev 2010:1-14.

-5 Clark DJ, Fondrie WE, Liao Z, Hanson PI, Fulton A, Mao L, Yang AJ: Redefining the breast cancer exosome proteome by tandem mass tag quantitative proteomics and multivariate cluster analysis. Anal Chem 2015;87:10462-10469.

6 Lin HC, Zhang FL, Geng Q Yu T, Cui YQ Liu XH, Li J, Yan MX, Liu L, He XH, Li JJ, Yao M: Quantitative proteomic analysis identifies CPNE3 as a novel metastasis-promoting gene in NSCLC. J Proteome Res 2013;12:3423-3433.

7 Neverova I, Van Eyk JE: Application of reversed phase high performance liquid chromatography for subproteomic analysis of cardiac muscle. Proteomics 2002;2:22-31.

8 Chou HC, Chen YW, Lee TR, Wu FS, Chan HT, Lyu PC, Timms JF, Chan HL: Proteomics study of oxidative stress and Src kinase inhibition in H9C2 cardiomyocytes: A cell model of heart ischemia-reperfusion injury and treatment. Free Radic Biol Med 2010;49:96-108.

-9 Wu XL, Zheng B, Jin LS, Zhang RN, He M, Yang Z, Wen JK: Chinese medicine Tongxinluo reduces atherosclerotic lesion by attenuating oxidative stress and inflammation in microvascular endothelial cells. Int J Clin Exp Pathol 2015;8:6323-6333. 


\section{Cellular Physiology Cell Physiol Biochem 2017;41:1503-1518 \begin{tabular}{l|l|l} 
and Biochemistry Publisned onIIne: IVIarch 24, 2017 & $\begin{array}{l}\text { (c) } 2017 \text { The Author(s). Published by S. Karger AG, Basel } \\
\text { www.karger.com/cpb }\end{array}$
\end{tabular}}

10 Dai W, Wei C, Kong H, Jia Z, Han J, Zhang F, Wu Z, Gu Y, Chen S, Gu Q, Lu X, Wu Y, Xu G: Effect of the traditional Chinese medicine tongxinluo on endothelial dysfunction rats studied by using urinary metabonomics based on liquid chromatography-mass spectrometry. J Pharm Biomed Anal 2011;56:86-92.

-11 Cui H, Li X, Li N, Qi K, Li Q Jin C, Zhang Q, Jiang L, Yang Y: Induction of autophagy by tongxinluo through the MEK/ERK pathway protects human cardiac microvascular endothelial cells from Hypoxia/Reoxygenation injury. J Cardiovasc Pharm 2014;64:180-190.

-12 Liang JQ, Wu K, Jia ZH, Liu C, Ding J, Huang SN, Yin PP, Wu XC, Wei C, Wu YL, Wang HY: Chinese medicine Tongxinluo modulates vascular endothelial function by inducing eNOS expression via the PI-3K/Akt/HIFdependent signaling pathway. J Ethnopharmacol 2011;133:517-523.

13 Li XD, Yang YJ, Geng YJ, Jin C, Hu FH, Zhao JL, Zhang HT, Cheng YT, Qian HY, Wang LL, Zhang BJ, Wu YL: Tongxinluo reduces myocardial no-reflow and ischemia-reperfusion injury by stimulating the phosphorylation of eNOS via the PKA pathway. Am J Physiol Heart Circ Physiol 2010;299:H1255-H1261.

14 Zhang RN, Zheng B, Li LM, Zhang J, Zhang XH, Wen JK: Tongxinluo inhibits vascular inflammation and neointimal hyperplasia through blockade of the positive feedback loop between miR-155 and TNF-alpha. Am J Physiol Heart Circ Physiol 2014;307:H552-H562.

15 Maes E, Valkenborg D, Baggerman G, Willems H, Landuyt B, Schoofs L, Mertens I: Determination of variation parameters as a crucial step in designing TMT-based clinical proteomics experiments. Plos One 2015;10:e120115.

-16 Hedhli N, Huang Q Kalinowski A, Palmeri M, Hu X, Russell RR, Russell KS: Endothelium-derived neuregulin protects the heart against ischemic injury. Circulation 2011;123:2254-2262.

-17 Bai WW, Xing YF, Wang B, Lu XT, Wang YB, Sun YY, Liu XQ, Guo T, Zhao YX: Tongxinluo improves cardiac function and ameliorates ventricular remodeling in mice model of myocardial infarction through enhancing angiogenesis. Evid Based Complement Alternat Med 2013;2013:813247.

18 Li YN, Wang XJ, Li B, Liu K, Qi JS, Liu BH, Tian Y: Tongxinluo inhibits cyclooxygenase-2, inducible nitric oxide synthase, hypoxia-inducible factor-2alpha/vascular endothelial growth factor to antagonize injury in hypoxia-stimulated cardiac microvascular endothelial cells. Chin Med J (Engl) 2015;128:1114-1120.

19 Chan GKL, Witkowski A, Gantz DL, Zhang TO, Zanni MT, Jayaraman S, Cavigiolio G: Myeloperoxidasemediated methionine oxidation promotes an amyloidogenic outcome for apolipoprotein A-I. J Biol Chem 2015;290:10958-10971.

20 Haschemi A, Kosma P, Gille L, Evans CR, Burant CF, Starkl P, Knapp B, Haas R, Schmid JA, Jandl C, Amir S, Lubec G, Park J, Esterbauer H, Bilban M, Brizuela L, Pospisilik JA, Otterbein LE, Wagner O: The sedoheptulose kinase CARKL directs macrophage polarization through control of glucose metabolism. Cell Metab 2012;15:813-826.

21 Muratli S, Uzunlulu M, Gonenli G, Oguz A, Isbilen B: Fetuin a as a new marker of inflammation in Hashimoto thyroiditis. Minerva Endocrinol 2015;40:9-14.

22 Shimizu M JTKN: Transplacental transport of $\alpha 2$-microglobulin $(\alpha 2 \mathrm{M})$ and induction of $\alpha 2 \mathrm{M}$ in maternal and neonatal rats with acute inflammation. Exp Anim 2002;4:361-365.

23 Bi Y, He Y, Huang J, Su Y, Zhu GH, Wang Y, Qiao M, Zhang BQ, Zhang H, Wang Z, Liu W, Cui J, Kang Q, Zhang Z, Deng Y, Li R, Zhang Q, Yang K, Luu HH, Haydon RC, He TC, Tang N: Functional characteristics of reversibly immortalized hepatic progenitor cells derived from mouse embryonic liver. Cell Physiol Biochem 2014;34:1318-1338.

24 Shoji H, Oguchi S, Shinohara K, Shimizu T, Yamashiro Y: Effects of iron-unsaturated human lactoferrin on hydrogen peroxide-induced oxidative damage in intestinal epithelial cells. Pediatr Res 2007;61:89-92.

-25 Zhang T, Wang Y, Ban R, Tong L, Qiao H, Lao H, Zhao H, Jiang X, Sun X, Zhang F: Oral administration of lactoferrin attenuates intestinal Ischemia-Reperfusion injury in rats. Eur Surg Res 2012;49:99-106.

-26 Ambrosio G, Weisman HF, Mannisi JA, Becker LC: Progressive impairment of regional myocardial perfusion after initial restoration of postischemic blood flow. Circulation 1989;80:1846-1861.

27 Leucker TM, Bienengraeber M, Muravyeva M, Baotic I, Weihrauch D, Brzezinska AK, Warltier DC, Kersten JR, Pratt PJ: Endothelial-cardiomyocyte crosstalk enhances pharmacological cardioprotection. J Mol Cell Cardiol 2011;51:803-811.

-28 Chen W, Yang S, Ping W, Fu X, Xu Q, Wang J: CYP2J2 and EETs protect against lung ischemia/reperfusion injury via anti-inflammatory effects in vivo and in vitro. Cell Physiol Biochem 2015;35:2043-2054.

29 HF G, NR W: Physiology of the endothelium. Br J Anaesth 2004;1:105-113. 


\section{Cellular Physiology Cell Physiol Biochem 2017;41:1503-1518 \begin{tabular}{ll|l} 
DOI: 10.1159/000470806 & Ond Biochemistry 2017 The Author(s). Published by S. Karger AG, Basel \\
wwww.karger.com/cpb
\end{tabular}

-30 Briaud SA, Ding ZM, Michael LH, Entman ML, Daniel S, Ballantyne CM: Leukocyte trafficking and myocardial reperfusion injury in ICAM-1/P-selectin-knockout mice. Am J Physiol Heart Circ Physiol 2001;280:H60-H67.

- 31 Lenglet S, Montecucco F, Mach F, Schaller K, Gasche Y, Copin JC: Analysis of the expression of nine secreted matrix metalloproteinases and their endogenous inhibitors in the brain of mice subjected to ischaemic stroke. Thromb Haemost 2014;112:363-378.

-32 Xie LN, Zeng DY, Zhang HS, Sun DM, Pang XF, Guan QG: Effect of tongxinluo on vasoconstriction induced by the chronic injury of the adventitia in the rat carotid artery. J Ethnopharmacol 2010;131:300-305.

-33 Li XD, Yang YJ, Cheng YT, Dou KF, Tian Y, Meng XM: Protein kinase A-mediated cardioprotection of Tongxinluo relates to the inhibition of myocardial inflammation, apoptosis, and edema in reperfused swine hearts. Chin Med J (Engl) 2013;126:1469-1479.

34 Cheng YT, Yang YJ, Zhang HT, Qian HY, Zhao JL, Meng XM, Luo FL, Wu YL: Pretreatment with Tongxinluo protects porcine myocardium from ischaemia/reperfusion injury through a nitric oxide related mechanism. Chin Med J (Engl) 2009;122:1529-1538.

-35 Liu M, Li H, Chang Y, Wu M, Chen LO: Proteomic analysis of stress-related proteins in transgenic broccoli harboring a gene for cytokinin production during postharvest senescence. Plant Sci 2011;181:288-299.

-36 Zhu T, Yao Q, Hu X, Chen C, Yao H, Chao J: The role of MCPIP1 in Ischemia/Reperfusion Injury-Induced HUVEC migration and apoptosis. Cell Physiol Biochem 2015;37:577-591.

- 37 Jang C, Koh YJ, Lim NK, Kang HJ, Kim DH, Park SK, Lee GM, Jeon CJ, Koh GY: Angiopoietin-2 exocytosis is stimulated by sphingosine-1-phosphate in human blood and lymphatic endothelial cells. Arterioscler Thromb Vasc Biol 2009;29:401-407.

-38 Fiedler U, Scharpfenecker M, Koidl S, Hegen A, Grunow V, Schmidt JM, Kriz W, Thurston G, Augustin HG: The Tie-2 ligand angiopoietin-2 is stored in and rapidly released upon stimulation from endothelial cell WeibelPalade bodies. Blood 2004;103:4150-4156.

- 39 Syrjälä SO, Tuuminen R, Nykänen AI, Raissadati A, Dashkevich A, Keränen MAI, Arnaudova R, Krebs R, Leow CC, Saharinen P, Alitalo K, Lemström KB: Angiopoietin-2 inhibition prevents transplant IschemiaReperfusion injury and chronic rejection in rat cardiac allografts. Am J Transplant 2014;14:1096-1108.

40 Pi L, Ding X, Jorgensen M, Pan JJ, Oh SH, Pintilie D, Brown A, Song WY, Petersen BE: Connective tissue growth factor with a novel fibronectin binding site promotes cell adhesion and migration during rat oval cell activation. Hepatology 2008;47:996-1004.

-41 Lee SW, Won JY, Kim WJ, Lee J, Kim KH, Youn SW, Kim JY, Lee EJ, Kim YJ, Kim KW, Kim HS: Snail as a potential target molecule in cardiac fibrosis: Paracrine action of endothelial cells on fibroblasts through snail and CTGF axis. Mol Ther 2013;21:1767-1777.

42 Clarke RL, Yzaguirre AD, Yashiro-Ohtani Y, Bondue A, Blanpain C, Pear WS, Speck NA, Keller G: The expression of Sox17 identifies and regulates haemogenic endothelium. Nat Cell Biol 2013;15:502-510.

-43 Kinderlerer AR, Pombo GI, Hamdulay SS, Ali F, Steinberg R, Silva G, Ali N, Wang B, Haskard DO, Soares MP, Mason JC: Heme oxygenase-1 expression enhances vascular endothelial resistance to complementmediated injury through induction of decay-accelerating factor: A role for increased bilirubin and ferritin. Blood 2009;113:1598-1607.

-44 Tegla CA, Cudrici CD, Azimzadeh P, Singh AK, Trippe RR, Khan A, Chen H, Andrian-Albescu M, Royal WR, Bever C, Rus V, Rus H: Dual role of Response gene to complement-32 in multiple sclerosis. Exp Mol Pathol 2013;94:17-28. 